\title{
Defining New Colorectal Cancer Syndromes in a Population-based Cohort of the Disease
}

\author{
ANNA FORSBERG ${ }^{1}$, ANNE KERÄNEN $^{2}$, SUSANNA VON HOLST ${ }^{3}$, SIMONE PICELLI $^{3}$, \\ NIKOS PAPADOGIANNAKIS ${ }^{2}$, SAM GHAZI $^{2}$ and ANNIKA LINDBLOM ${ }^{1}$ \\ ${ }^{1}$ Karolinska Institutet, Department of Medicine Solna, Karolinska University Hospital, Stockholm, Sweden; \\ ${ }^{2}$ Karolinska Institutet, Department of Laboratory Medicine, Division of Pathology, \\ Karolinska University Hospital, Stockholm, Sweden; \\ ${ }^{3}$ Karolinska Institutet, Department of Molecular Medicine and Surgery, \\ Karolinska University Hospital, Stockholm, Sweden
}

\begin{abstract}
Background/Aim: Most known cancer syndromes confer an increased risk of more than one tumour types, and families with more than one colorectal cancer often segregate other cancers as well. The aim of this study was to examine if there is a general increased risk of other cancers in colorectal cancer families, which are defined as having two or more cases of colorectal cancer in close relatives. Materials and Methods: The study used a detailed family history of cancer diagnoses in a cohort of more than 3,000 consecutive colorectal cancer cases. A comparison was made between families with sporadic and those with familial colorectal cancer cases. Detailed morphology data were used to find further support for putative syndromes. Results: There were significantly more non-colorectal cancers in the family history of the familial CRC cases $(p<0.001)$, with significantly more gastric cancers $(p<0.001)$, prostate cancers $(p<0.001)$, urinary bladder cancers $(p<0.001)$ and melanomas $(p=0.002)$, leukaemia/lymphomas $(p=0.004)$, gynaecological cancers ( $p=0.007)$ and breast cancers $(p=0.023)$. There was also some support for different morphological profiles for four of the five tested syndromes. Conclusion: This study found support for a general increased risk of one or more different cancer syndromes involving families with colorectal cancer and other cancers. Further studies will define the different possible syndromes and determine the genetic background.
\end{abstract}

This article is freely accessible online.

Correspondence to: Annika Lindblom, Department of Molecular Medicine and Surgery, Karolinska University Hospital, Solna, Karolinska Institutet L8:02, S-17176 Stockholm, Sweden. E-mail: annika.lindblom@ki.se

Key Words: Colorectal cancer, familial, syndrome, prevention.
Colorectal cancer (CRC) is the third most common form of cancer in Sweden (1). It contributes to about $7 \%$ of all cancer diagnoses and is the fourth leading cause of death in cancer worldwide (1). CRC can be prevented by the detection and removal of precursor lesions, e.g. adenomatous polyps; therefore, population-based screening, most often using fecal occult blood testing, is offered in many countries to populations over a threshold age. This necessitates defining the risk populations shown to benefit from screening and offering them tailored surveillance programs. A few high-risk syndromes are known to be associated with an increased risk of CRC, familial adenomatous polyposis (FAP) and Lynch syndrome (LS). The genes causing these syndromes are known, and genetic counselling and presymptomatic testing is offered in clinical settings and surveillance programs have been established (2). However, only a small fraction of families being counselled for an increased risk of CRC segregate into these known syndromes. More than $20 \%$ of all new CRC cases have a family history of CRC in close relatives, and less than 5\% have FAP or LS (3). These families could be counselled and risks could be estimated based on family history (4). Still, it would be of value to define the remaining predisposing genetic contributions in order to offer genetic testing in these families, as well. Studies have aimed at defining additional non-FAP, non-LS syndromes as familial colorectal cancer type X (5), including the ones defining Amsterdam I families without microsatellite instability (MSI). The hypothesis of the existence of additional high-risk monogenic syndromes has been supported by several studies $(3,5)$. Evidence for rectal cancer as a separately inherited entity has been published (6), as well as a syndrome of familial CRC associated with serrated adenomas (7). A syndrome of mixed polyps, have recently been defined as distinct entity with the genetic background identified (8). Some familial CRCs and sporadic CRCs could be explained by defining CRC as a 
complex disease, and several genome-wide association studies (GWAS) have aimed to define this proportion (9). Still, the low-risk alleles known today explain only a small portion of all CRCs.

We had observed that non-FAP/LS families with CRC, even more than in LS families, seem to segregate many other kinds of cancers, which is why we set out to use the family history of cancer to define new CRC syndromes. A cohort of consecutive CRC cases from central Sweden was used, and family history of sporadic cancer cases were compared with those of familial cases. In addition, we used tumour phenotypes to find support for suggested syndromes.

\section{Materials and Methods}

Patients. During the years 2004 through 2009, more than 3,300 patients in 14 hospitals in the area of Stockholm, underwent surgery for CRC. All gave informed consent and blood for genetic studies and were included in the Colorectal Cancer Low-risk study. The same person interviewed all patients about their family history of cancer, including colorectal cancer and other malignancies. Cancer occurrences in first- and second-degree relatives and cousins were recorded, and pedigrees for the families of the index-person (the patient) were constructed. All diagnoses that could have been CRC were verified using medical records or death certificates. Other diagnoses were coded as stated by the index patient. Because of difficulties defining the exact diagnosis, all haematological malignancies were coded as one entity, as were all gynaecological cancers. Cases with no relative diagnosed with CRC were considered sporadic. Familial CRC cases were defined as having at least one relative with $\mathrm{CRC}$, as defined above. FAP was diagnosed by the pathology report of the index patient. Four FAP cases were thus identified and excluded from further studies. A combination of CRC family history, early age onset and tumour testing was used to diagnose Lynch syndrome (10). In total, 422 MSI-tests, 69 BRAF tests and 158 immunohistochemistry tests were performed. Based on the results, 94 patients were sequenced and 28 cases with Lynch syndrome were found and excluded from further studies. Based on medical records, the sex, age and tumour location of the index-patients were recorded. Tumours were assigned locations in the caecum, ascending colon, hepatic flexure, transverse colon, splenic flexure, descending colon and the sigmoid or rectum. This study was approved by the local Ethics Committee at Karolinska Institutet (no. KI Dnr 02-489).

Pathology. All tumours underwent evaluation by a local pathologist directly after surgery. Within the morphology study, 1,612 samples were available at the time and used for re-examination. The initial 18 cases $(1.1 \%)$ were evaluated by two experienced gastrointestinal pathologists (S.G. and N.P.) to discuss and establish consensus criteria regarding the morphological parameters. The remaining cases were evaluated by one pathologist (S.G.). In the study of differences in morphology, cancer families were defined as families with at least two CRCs and two or more other types of cancers in first- or second-degree relatives or cousins. In the morphology analysis, tumours were grouped into right-sided (caecum through transverse colon) and left-sided (splenic flexure through rectum). The tumours were staged according to both the American Joint Committee on Cancer (AJCC) classification and the tumour, node, and metastases (TNM) systems. Rectal tumours were classified in
Table I. Descriptive data.

\begin{tabular}{|c|c|c|c|c|}
\hline \multicolumn{5}{|l|}{ Gender and age } \\
\hline & Total & Men & Women & $p$-Value \\
\hline Number $(\%)$ & 3,214 & $1,753(55 \%)$ & $1,461(45 \%)$ & \\
\hline Mean age (SD) & $68.3(10.9)$ & $68.5(10.6)$ & $68.1(11.2)$ & NS $(0.29)$ \\
\hline \multicolumn{5}{|c|}{ Prevalence family history and age } \\
\hline & Total & Sporadic & Familial & $p$-Value \\
\hline Number $(\%)$ & 3214 & $2509(78 \%)$ & $705(22 \%)$ & \\
\hline Mean age (SD) & $68.3(10.9)$ & $68.6(10.9)$ & $67.3(10.0)$ & 0.004 \\
\hline
\end{tabular}

NS, Not specified.

accordance with the surgeon's report $(15 \mathrm{~cm}$ or less from the anal verge). Nine patients were excluded from the location analyses because they had cancers in more than one segment; however, some patients with two or more tumours could be classified when the tumours were located within the same segment.

A specific protocol was submitted for each tumour. The following data were analyzed: degree of differentiation in the major part of the tumour, mucin production, Crohn-like peritumoural lymphocytic infiltration, tumour infiltrating lymphocytes (TILs), desmoplastic reaction, necrosis, invasion of blood or lymph vessels, perineural growth, medullary type, budding and tumour margin. The exact definition of each morphological feature and how they were assessed has been outlined in detail in a previous report (11).

Statistical analysis. Analysis on population cohort. Statistical analyses were performed using Statistica 7.0 (StatSoft., Inc, Tulsa, OK, USA), and the methods used were the Mann-Whitney $U$-test, Students T-test and Speaerman's rank-order analysis.

Analysis on morphology: Correlation between syndromes and morphology was investigated using cross tabulation-analysis and the Pearson $\chi^{2}$-test. A $p$-value of $<0.05$ was considered significant, but non-significant $p$-values were also recorded.

\section{Results}

In total, 1,753 men and 1,461 women were included in the study. There was no gender difference in age of onset, but familial cases were slightly younger $(p=0.004)$ (Table I).

The number of non-CRC cases was compared between the families of the sporadic and familial CRC cases (Table II). The comparison was applied for number of families with any case of cancer other than CRC and for each of the 12 types of cancers reported. There were significantly more other cancers in the family history of the familial CRC cases $(p<0.001)$ with significantly more gastric cancers $(p<0.001)$, prostate cancers $(p<0.001)$, urinary bladder cancers $(p<0.001)$ and melanomas $(p=0.002)$, leukaemia/lymphoma $(p=0.004)$, gynaecological cancers $(p=0.007)$ and breast cancers $(p=0.023)$. It is not possible to say whether the 
Table II. Comparison of prevalence of other cancer than colorectal within families with sporadic and with familial colorectal cancer.

\begin{tabular}{|c|c|c|c|c|}
\hline Type of cancer & $\begin{array}{c}\text { Sporadic } \mathrm{N}=2509 \\
\mathrm{~N} \text { families with } \\
\text { cancer }(\%) \\
\text { Mean } \\
\mathrm{N} \text { individuals } \\
\text { (range) }\end{array}$ & $\begin{array}{c}\text { Familial } \mathrm{N}=705 \\
\mathrm{~N} \text { families with } \\
\text { cancer }(\%) \\
\text { Mean } \\
\mathrm{N} \text { individuals } \\
\text { (range) }\end{array}$ & $\begin{array}{l}\text { Z-value } \\
\text { corr }\end{array}$ & $p$-Value \\
\hline Breast & $\begin{array}{c}543(22) \\
0.29(0-6)\end{array}$ & $\begin{array}{c}182(26) \\
0.40(0-4)\end{array}$ & -2.28 & 0.023 \\
\hline Pancreas & $\begin{array}{c}132(5) \\
0.06(0-4)\end{array}$ & $\begin{array}{c}37(5) \\
0.06(0-2)\end{array}$ & 0.02 & 0.99 \\
\hline Stomach & $\begin{array}{c}439(19) \\
0.21(0-5)\end{array}$ & $\begin{array}{c}163(23) \\
0.29(0-5)\end{array}$ & -3.45 & $<0.001$ \\
\hline Prostate & $\begin{array}{c}383(15) \\
0.19(0-5)\end{array}$ & $\begin{array}{c}151(21) \\
0.28(0-5)\end{array}$ & -3.97 & $<0.001$ \\
\hline Gynecological & $\begin{array}{c}319(13) \\
0.15(0-3)\end{array}$ & $\begin{array}{c}117(17) \\
0.20(0-4)\end{array}$ & -2.67 & 0.007 \\
\hline Biliary tract & $\begin{array}{c}38(2) \\
0.01(0-2)\end{array}$ & $\begin{array}{c}14(2) \\
0.02(0-2)\end{array}$ & -0.88 & 0.38 \\
\hline Pulmonary & $\begin{array}{c}333(13) \\
0.16(0-5)\end{array}$ & $\begin{array}{c}90(13) \\
0.15(0-5)\end{array}$ & 0.40 & 0.69 \\
\hline Urinary bladder & $\begin{array}{c}60(2) \\
0.03(0-2)\end{array}$ & $\begin{array}{c}40(6) \\
0.06(0-2)\end{array}$ & -4.43 & $<0.001$ \\
\hline $\begin{array}{l}\text { Leukemia/ } \\
\text { lymphoma }\end{array}$ & $\begin{array}{c}253(10) \\
0.11(0-5)\end{array}$ & $\begin{array}{c}98(14) \\
0.17(0-5)\end{array}$ & -2.91 & 0.004 \\
\hline Melanoma & $\begin{array}{c}103(4) \\
0.05(0-4)\end{array}$ & $\begin{array}{c}49(7) \\
0.08(0-2)\end{array}$ & -3.14 & 0.002 \\
\hline Brain & $\begin{array}{c}158(6) \\
0.07(0-2)\end{array}$ & $\begin{array}{c}54(8) \\
0.09(0-3)\end{array}$ & -1.30 & 0.19 \\
\hline Kidney & $\begin{array}{c}90(4) \\
0.04(0-3)\end{array}$ & $\begin{array}{c}28(4) \\
0.04(0-2)\end{array}$ & -0.48 & 0.63 \\
\hline Other cancer & $\begin{array}{c}865(34) \\
0.48(0-5)\end{array}$ & $\begin{array}{c}295(42) \\
0.61(0-7)\end{array}$ & -3.60 & 0.003 \\
\hline Any cancer & $\begin{array}{c}1894(75) \\
1.84(0-14)\end{array}$ & $\begin{array}{c}581(82) \\
2.28(0-12)\end{array}$ & -6.56 & $<0.001$ \\
\hline
\end{tabular}

Comparison between the families classified as "sporadic" and as "familial" is performed by the Mann-Whitney-test. For each type of cancer, the number of families with one or more affected individual is noted. The mean number of affected individuals per family and the range is also noted. A $p$-value $<0.05$ indicates that the cancer form is clustered in families classified as familial colorectal cancer.

results represent one or many different syndromes and combinations of tumours.

To find some support for possible morphological markers to be associated with a putative syndrome, we studied CRC morphology in the index patient in relation to five of the different suggested syndromes: cancer families, CRC and bladder cancer families, CRC and prostate cancer families, CRC and melanoma families and CRC and gastric cancer families (Table III). There was some support for different morphological profiles for four of the five tested syndromes. The colorectal tumours in the cancer families more often showed vascular invasion $(p=0.017)$ and poor differentiation
Table III. CRC morphology in the index case in relation to the different suggested syndromes. CRC morphology in the index case in relation to the different suggested syndroms $(N=1612)$.

\begin{tabular}{lccccc}
\hline & $\begin{array}{c}\text { Cancer } \\
\text { family* }\end{array}$ & $\begin{array}{c}\text { CRC+ } \\
\text { bladder }\end{array}$ & $\begin{array}{c}\text { CRC+ } \\
\text { prostate }\end{array}$ & $\begin{array}{c}\text { CRC+ } \\
\text { melanoma }\end{array}$ & $\begin{array}{c}\text { CRC+ } \\
\text { gastric }\end{array}$ \\
\hline Differentiation $^{\dagger}$ & $0.044^{* *}$ & 0.472 & 0.625 & 0.030 & 0.877 \\
Mucin production $^{*}$ & 0.138 & 0.904 & 0.125 & 0.355 & 0.139 \\
Peritumoural $^{\dagger}$ & 0.680 & 0.429 & 0.435 & 0.615 & 0.012 \\
TILs $^{\dagger \dagger}$ & 0.410 & 0.474 & 0.871 & 0.883 & 0.802 \\
Desmoplasia $_{\text {Necrosis }}$ & 0.785 & 0.789 & 0.519 & 0.379 & 0.702 \\
Vascular invasion $^{\ddagger}$ & 0.833 & 0.297 & 0.369 & 0.333 & 0.818 \\
Perineural growth & 0.017 & 0.482 & 0.873 & 0.665 & 0.750 \\
Medullary type & 0.842 & 1.000 & 0.231 & 0.269 & 0.324 \\
Budding ${ }^{\ddagger \ddagger}$ & 1.000 & 0.507 & 0.423 & 0.106 & 1.000 \\
Invasive margin & 0.639 & 1.000 & 0.009 & 0.914 & 0.446 \\
\hline & 0.346 & 0.316 & 0.190 & 0.547 & 0.127 \\
\hline
\end{tabular}

* Families with at least two CRCs and two or more other types of cancer, in first or second-degree relatives or cousins. ${ }^{* *} p$-values for correlation between CRC syndrome and morphological features. ${ }^{\dagger}$ Poor differentiation in the major part of the tumour. ${ }^{\dagger}$ Peritumoural Crohnlike lymphocytic reaction. ††More than 30 tumour infiltrating lymphocytes per 10 high-power fields. + Unequivocal tumour aggregates in preformed spaces lined by endothelium. $¥$ Detachment of single isolated cancer cells or a cluster of up to four cells.

( $p=0.044)$. The tumours in the CRC and prostate families were associated with budding $(p=0.009)$. Patients from CRC-melanoma families showed a correlation to poor differentiation $(p=0.030)$, and patients from CRC and gastric cancer families more often had tumours with Crohn-like peritumoural lymphocytic reaction $(p=0.012)$.

\section{Discussion}

Known cancer syndromes often involve an increased risk for a whole spectrum of tumours, such as CRC, endometrial, gastric, renal pelvis and other tumours in LS and breast cancer, leukemia, sarcoma, as well as brain tumours in LiFraumeni syndrome $(12,13)$. Also, for the $B R C A 1, B R C A 2$ and $A P C$ genes and, in fact, almost all known cancer genes, a typical spectrum of different cancers is associated with each gene involved in the syndrome (14-16).

When CRCs cluster in families where none of the known syndromes are prevalent, other tumours are also frequently seen. To find out if this was significant, we used a cohort of consecutive CRC cases and their family history of cancer among close relatives for the study. After comparing the family history it was clear that several tumours were more prevalent in the families with more than one CRC case. It is difficult to determine whether there was only one cancer family syndrome with a differently increased risk for many cancers, or several different syndromes - including several 
different tumour spectra. We tested tumour types separately and found a positive statistically significant association for urinary bladder, prostate and gastric cancer, melanoma, leukemia/lymphoma groups and gynecological cancer. Compared to the strong association with even rare tumours such as urinary bladder and gastric cancer, the association with breast cancer is weaker and more uncertain. It is at least likely that specificity for one or several CRC syndromes exists, but without knowledge of the underlying genetic contribution, it is impossible to say what tumours are associated with each syndrome.

One limitation of our study is that not all the diagnoses among family members were verified through medical records. However, all abdominal malignancies with an unclear diagnosis were verified in order to confirm or exclude CRC. Other diagnoses were coded as reported from the index patient, if stated in detail and claiming good knowledge. Weak remembrance or uncertainty resulted in our not coding a cancer diagnosis. Some malignancies were considered more uncertain than others. So, for example, gynecological malignancies and hematological malignancies were often stated as such and we rarely specified in detail why we chose to use these terms for all cases reported, regardless of how specifically the diagnoses were expressed. Another limitation is that we did not adjust for differences in family size. It is possible that some families reported more cancers because of larger family size; thus, large families with at least two cases of CRC should show more cancers. However, the prevalence of two close relatives with CRC is associated with an increased risk of CRC for other close relatives, but was not known until now to be associated with other cancers (4).

We used family history and tumour testing to select cases for genetic testing and diagnosis of Lynch syndrome. Only about $1.2 \%$ of the patients in Sweden should have LS, judging from a previous study (17). Using the strategy in the present study excluded $1 \%$ of the cases with Lynch syndrome based on molecular genetic testing for Lynch syndrome. Even if our strategy might have missed a few cases, such a small proportion is not likely to influence our results. Considering the results and the suggested syndromic tumours, only gastric cancer is clearly associated with LS (12); however, it is rarely seen in Swedish families. Melanoma has not been reported to be overrepresented in LS, and prostate cancer has been reported to be more common in LS-gene carriers than among the general population (18), although this might relate to the selection of families (19). Gynecological cancer constitutes typical tumours of the LS, but endometrial cancer was associated with CRC in both LS and non-LS families who have undergone genetic testing at our clinic at Karolinska Institute, Sweden.

An effort was made to find more evidence in support of the suggested new syndrome(s). Predisposed CRC genes are typically morphogens, thus CRC tumours will demonstrate different morphology depending on the underlying genetic contribution (20). Morphological data was available from half of the patient material (11). Tumour morphology in the index patients was used for testing the hypothesis that tumours in five different syndromes might show different and typical phenotypic characteristics to support different underlying genetic etiology. Gynecological malignancies and hematological malignancies were excluded in the subsequent morphology study. Both groups included tumours not specified in detail and were therefore possibly heterogenous and more uncertain. Breast cancer was also excluded due to its weak association to CRC $(p=0.023)$, even though it is a common cancer. We found statistically significant associations for four of five hypothetical syndromes tested: cancer families, CRC-prostate cancer families, CRCmelanoma families and CRC-gastric cancer families. Since this is the first study of a detailed morphology associated with new CRC cancer syndromes, we thought it was relevant to show all possible results and chose to not correct for multiple testing; therefore, false positives cannot be ruled out from some of our results. The findings included few of the 11 tested tumour characteristics, which does not provide strong evidence for any specific syndrome. Nevertheless, the results still support a different underlying genetic cause of putative cancer syndromes.

Data form this study suggest that there are one or more different colorectal cancer syndromes (Lynch syndrome excluded) involving gastric cancer, prostate cancer, urinary bladder cancer, melanomas, leukemia/lymphosas, gynecolocical cancers and/or breast cancer.

\section{Conclusion}

In conclusion, we used the family history of cancer in relatives of consecutive CRC patients to define new putative CRC syndromes. Morphological analysis revealed some support. The rationale for this report was to define new syndromes that could be used for future studies of new predisposing genes. Further studies aiming to find the underlying genetic contribution must be undertaken to test new hypothetical colorectal cancer syndromes.

\section{Conflicts of Interest}

The Authors declare that they have no conflict of interest.

\section{Acknowledgements}

We thank all patients and their spouses. We also thank Berith Wejderot for excellent technical assistance.

The study was supported by grants provided by the Swedish Cancer Society (Cancerfonden), the Stockholm County Council (ALF project), the Swedish Research Council (Vetenskapsrådet), the Stockholm Cancer Society (Radiumhemsfonderna) and Bert von Kantzows and Nilsson-Ehle's foundations. 


\section{References}

1 Cancer fact sheet number 297. World Health Organization (2010). Geneva. www.who.int/mediacentre/factsheets/fs297. Accessed January 2017.

2 Lynch HT, Lynch JF, Lynch PM and Attard T: Hereditary colorectal cancer syndromes: molecular genetics, genetic counseling, diagnosis and management. Fam Cancer 7(1): $27-$ 39, 2008.

3 Aaltonen L, Johns L, Järvinen H, Mecklin JP and Houlson R: Explaining the familial colorectal cancer risk associated with mismatch repair (MMR)-deficient and MMR-stable tumors. Clin Cancer Res 13: 356-361, 2007.

4 Johns LE and Houlston RS: A systematic review and metaanalysis of familial colorectal cancer risk. Am J Gastroenterol 96: 2992-3003, 2001.

5 Lindor NM, Rabe K, Petersen GM, Haile R, Casey G, Baron J, Gallinger S, Bapat B, Aronson M, Hopper J, Jass J, LeMarchand L, Grove J, Potter J, Newcomb P, Terdiman JP, Conrad P, Moslein G, Goldberg R, Ziogas A, Anton-Culver H, de Andrade M, Siegmund K, Thibodeau SN, Boardman LA and Seminara D: Lower cancer incidence in Amsterdam-I criteria families without mismatch repair deficiency: familial colorectal cancer type $\mathrm{X}$. JAMA 293: 1979-1985, 2005.

6 Abdel-Rahman WM and Peltomäki P: Lynch syndrome and related familial colorectal cancers. Crit Rev Oncog 14: 1-31, 2008.

7 Young J, Barker MA, Simms LA, Walsh MD, Biden KG, Buchanan D, Buttenshaw R, Whitehall VL, Arnold S, Jackson L, Kambara T, Spring KJ, Jenkins MA, Walker GJ, Hopper JL, Leggett BA and Jass JR: Evidence for BRAF mutation and variable levels of microsatellite instability in a syndrome of familial colorectal cancer. Clin Gastroenterol Hepatol 3: 254263, 2005

8 Lieberman S, Walsh T, Schechter M, Adar T, Goldin E, Beeri R, Sharon N, Baris H, Ben Avi L, Half E, Lerer I, Shirts BH, Pritchard CC, Tomlinson I, King MC, Levy-Lahad E, Peretz T and Goldberg Y: Features of patients with hereditary mixed polyposis syndrome caused by duplication of GREM1 and implications for screening and surveillance. Gastroenterology pii: S0016-5085(17)30178-6, 2017. doi: 10.1053/j.gastro. 2017.02.014. [Epub ahead of print]

9 Al-Tassan NA, Whiffin N, Hosking FJ et al: A new GWAS and meta-analysis with 1000 Genomes imputation identifies novel risk variants for colorectal cancer. Sci Rep 5: 10442, 2015.

10 Lagerstedt-Robinson K, Rohlin A, Aravidis C Melin B, Nordling M, Stenmark-Askmalm M, Lindblom A and Nilbert M Mismatch repair gene mutation spectrum in the Swedish Lynch syndrome population. Oncol Rep 36(5): 2823-2835, 2016

11 Ghazi S, von Holst S, Picelli S, Lindforss U, Tenesa A, Farrington SM, Campbell H, Dunlop MG, Papadogiannakis N, Lindblom A and The Low-Risk Colorectal Cancer Study Group: Colorectal Cancer. Susceptibility Loci in a Population-Based Stud: Associations with Morphological Parameters. Am J Pathol 177: 2688-2693, 2010
12 Møller P, Seppälä T, Bernstein I, Holinski-Feder E, Sala P, Evans DG, Lindblom A, Macrae F, Blanco I, Sijmons R, Jeffries J, Vasen H, Burn J, Nakken S, Hovig E, Rødland EA, Tharmaratnam K, de Vos Tot Nederveen Cappel WH, Hill J, Wijnen J, Green K, Lalloo F, Sunde L, Mints M, Bertario L, Pineda M, Navarro M, Morak M, Renkonen-Sinisalo L, Frayling IM, Plazzer JP, Pylvanainen K, Sampson JR, Capella G, Mecklin JP and Möslein G; Mallorca Group (http://mallorca-group.eu). Cancer incidence and survival in Lynch syndrome patients receiving colonoscopic and gynaecological surveillance: first report from the prospective Lynch syndrome database. Gut 66(3): 464-472, 2017.

13 Yurgelun MB, Masciari S, Joshi VA, Mercado RC, Lindor NM, Gallinger S, Hopper JL, Jenkins MA, Buchanan DD, Newcomb PA, Potter JD, Haile RW, Kucherlapati R and Syngal S; Colon Cancer Family Registry: Colon Cancer Family Registry. Germline TP53 Mutations in Patients With Early-Onset Colorectal Cancer in the Colon Cancer Family Registry. JAMA Oncol 1(2): 214-221, 2015.

14 Vogelstein B and Kinzler KW: Cancer genes and the pathways they control. Nat Med 10(8): 789-799, 2004.

15 Mersch J, Jackson MA, Park M, Nebgen D, Peterson SK, Singletary C, Arun BK and Litton JK: Cancers associated with BRCA1 and BRCA2 mutations other than breast and ovarian. Cancer 121(2): 269-275, 2015.

16 Groen EJ, Roos A, Muntinghe FL, Enting RH, de Vries J, Kleibeuker JH, Witjes MJ, Links TP and van Beek AP: Extraintestinal manifestations of familial adenomatous polyposis. Ann Surg Oncol 15(9): 2439-2450, 2008.

17 Olsson L and Lindblom A: Family history of colorectal cancer in a Swedish county. Familial Cancer 2: 87-93, 2003.

18 Dominguez-Valentin M, Joost P, Therkildsen C, Jonsson M, Rambech E and Nilbert M: Frequent mismatch-repair defects link prostate cancer to Lynch syndrome. BMC Urol 16: 15, 2016.

19 Grindedal EM, Møller P, Eeles R, Stormorken AT, Bowitz-Lothe IM, Landrø SM, Clark N, Kvåle R, Shanley S and Maehle L: Germ-line mutations in mismatch repair genes associated with prostate cancer. Cancer Epidemiol Biomarkers Prev 18: 24602467,2009

20 van den Brink GR and Offerhaus GJ: The morphogenetic code and colon cancer development. Cancer Cell 11: 109-117, 2007.

Received February 22, 2017

Revised March 15, 2017

Accepted March 20, 2017 